\title{
Early construction of number as position with young children: a teaching experiment
}

Claire Margolinas

ACTé, EA 4281, Université Blaise Pascal, Clermont-Ferrand

claire.margolinas@univ-bpclermont.fr

Floriane Wozniak

IRIST EA 3424, Université de Strasbourg

floriane.wozniak@iufm.unistra.fr

Our study is motivated by the importance of the number line in the visualisation of elementary properties of operations and numbers. For the number line to be an aid for visualisation, first it must be conceived as a coordinate system (origin, orientation and unit). This paper focuses on the construction of the concept of position on a line, and on the number as a means of remembering position, for pre-elementary school children aged 5-6 years. Using didactic design as a methodology, we conducted an experiment to observe how knowledge was constructed while carrying out a certain kind of task in a situation where position had to be designated. Our study shows that pupils, despite recognising number as a quantity, fail to apprehend number as something which represents position. They are, however, capable of understanding the characteristic elements of the number line in suitable situations. Our research suggests that it is possible to teach the use of ordinal numbers to young pupils.

Number line, cardinal, ordinal, position, didactic design, kindergarten

\section{Introduction}

This investigation, as part of our work on numbers in kindergarten (Margolinas and Wozniak 2012), focuses on how children aged 5-6 years can learn to perceive position on a line and the use of a number to remember that position.

\subsection{A teaching experiment}

Task design lies at the very core of research in mathematics education (Sierpinska 2003; Wittman 1995), not only as a goal in order to better teach mathematics but also as a way to research pupils' knowledge in meaningful situations: 'in which mathematical ideas are useful, using the linked constructs of purpose and utility' (Ainley 2008, p. 1), similar to what Brousseau (1997) calls a 'fundamental situation' and Wittman a 'substantial learning environment' (1995, pp. 365-366). This study is consistent with the didactic design approach, which is conceived for the purposes of research (Artigue 1992; Artigue and Perrin-Glorian 1991; Chevallard 2012; Margolinas et al. 2011).

We can also regard our research as clinical teaching, described by Wittman (1995, pp. 367-368) very clearly:

[...] 'clinical teaching experiments' in which teaching units can be used not only as research tools, but also as objects of study.

The data collected in these experiments have multiple uses: they tell us something about the teaching/learning processes, individual and social outcomes of learning, children's productive thinking, and children's difficulties. They also help us to evaluate the unit and to revise it in order to make teaching and learning more efficient.

In this paper, we focus on 'children's productive thinking and children's difficulties' with ordinal numbers: we consider, like Tsamir et al. (2010), that pupils aged 5-6 years are capable of solving problems using several methods. Therefore we seek to contribute to question 4 of this issue of ZDM: What does progressive visualisation mean, including how it comes about, in classroom activity? In particular, we want to answer the two following research questions: How does the visualisation of the coordinate system evolve during the learning unit? How do pupils use numbers in order to memorise and represent a position? 


\subsection{The number line}

The number line plays an important role from the beginning of primary school in the visualisation of the properties of numbers (Csikos et al. 2012), even if the way in which this visualisation is used in class can be questioned (Ernest 1985; Van den Heuvel-Panhuizen 2008).

Ernest (1985) regards number lines not as a teaching aid but 'as direct contributors to components of the mathematics curriculum' (p. 423). We concur with him: 'In view of the widespread use of number line diagrams and models in school mathematics, the area needs further investigation and research' (p. 423).

The construction of number has often been researched (e.g. Comiti 1980; Fuson 1983; Gelman and Gallistel 1978; Piaget and Szeminska 1941). Most of these studies focus on oral number strings or on the cardinal aspect of numbers (Urbanska 1993; Wright 1994). However, this is not the case in the paper by Bruce and Threlfall (2004), which focuses on the ordinal aspect of numbers, and more precisely the oral expression of numbers: 'as a trigger to ordinal understanding' (p. 7). Their results show a great difference between the acquisition of number in a cardinal context and in an ordinal one. Thus, even if the pupils knew how to count, 'the use of that skill in an ordinal context was just not considered' (p. 21). Only one child in their sample of 93 attempted to determine position using counting as a strategy. They conclude 'that the relatively tardy development of ordinal number may be mostly the result of the attention given by adults, and the nature of the common experiences of young children in a pre-school setting' (p. 24).

We have therefore designed a sequence of tasks involving the position on a line, which is one way of defining an ordinal number, in order to focus young pupils' attention on this aspect of numbers. The aim of this exploratory research is to understand how pupils are able to visualise and represent position on a line and how this visualisation evolves during the designed sequence. In order to build a sequence of tasks on this theme, we first describe cardinal and ordinal numbers in a material setting.

\subsection{Cardinal numbers and ordinal numbers in our setting}

The material setting we have chosen is based on the following idea.

Take two identical bags in each of which there are nine white beads and one red bead. There are two identical sets from a quantitative point of view. Now take two bits of thread, each knotted at one end, and thread the beads from the two bags separately. There is only one chance out of ten for these two 'necklaces' to have the red beads in the same place with respect to the knot (one-to-one comparison of the position). Threading the beads has created an order: the red bead is in a particular position, which may not be the same in the two necklaces. The number which allows the necklaces to be differentiated no longer refers to the quantity of beads but to the position of the red bead among the white ones: for instance in second or third position. Thus a shift in meaning has been created: from the number as a remembered quantity - the cardinal number - to the number as a remembered position - the ordinal number. Our design is based on this use of the position of one coloured bead among neutral beads in necklaces of ten beads.

What defines a 'one-dimensional coordinate' remains implicit: a coordinate system in a onedimensional space (a line) comprises an origin and an orientation. Conceiving the number in order to remember a location on a line leads to conceiving an implicit linear coordinate system. ${ }^{1}$

\subsection{A 'formulation situation' to lead pupils towards the representation}

In contrast to the work of Bruce and Threlfall (2004), this study did not consider oral language as the only criterion for measuring the learning of the ordinal number. We wanted to explore the possibilities of the pupils producing written formulations in order to remember a position. Therefore, according to Brousseau's Theory of Situations (1997), we have to build a situation in which it is necessary to use a written representation in order to succeed. That is the purpose of 'formulation situations'.

In an 'action situation' (Brousseau 1997), the pupil seeks to carry on an action which gives tangible results; while in a formulation situation, the immediate action is delayed, making the recording of information necessary. To make a formulation situation clearer, we can look at

1 In the rest of this paper we write 'coordinate system' but here we are dealing only with one dimension. We are aware that in English it is sometimes called a 'number line' but this term is not suitable for our paper, since we have to consider the question of the coordinate system ("repère" in French) and the use of numbers separately. 
moments in real life. We thus illustrate the three commonest types of formulation situation, which were used in our didactic design.

The first impediment to immediate action corresponds to a distance between two places. Let us assume that you are doing repair work upstairs in your house but you need tools that are in your garage. You have to stop your action and ask yourself what you have to get. By contrast with an immediate action, where all the tools are present, it is necessary to become aware of the action to be fulfilled in order to find the right tool. The distance between the two places leads to postponing the action and transforms an activity of 'doing' into an activity of 'thinking about what to do'.

The second category of formulation situation corresponds to a distance between two moments. Let us take the case of shopping: you notice that you are lacking something but you will do the shopping later. It is in this type of situation that writing (making a shopping list) becomes necessary. Formulation situations with different distant moments thus play an important role in the development of mental images, which are themselves parts of visualisation (Arcavi 1999).

The last category of formulation situation corresponds to a communication with others. Let us assume that you are in a bakery. You have to ask for a baguette because you are not allowed to take it yourself. This communication can be oral or written (on-line shopping for example). Writing requires the transmitter to represent what is wanted (using words, diagrams or signs). When the roles of transmitter and receiver alternate, the receiver in becoming aware of the difficulty in understanding the message received can then become inspired to enrich his or her own representations. In the experiment we carried out, we were able to observe the catalyst role of this didactic situation for the pupils' representations.

The study of the pupils' written productions showed the way pupils graphically visualised the position and how this visualisation evolved over the situations.

\subsection{Written representation and conceptualisation of numbers as coordinates on the number line}

As Duval (1999, pp. 3-4) says, 'representation and visualization are at the core of understanding in mathematics' and 'there is no other way of gaining access to the mathematical objects but to produce some semiotic representation'. This point of view is shared by Bosch and Chevallard (1999): in Anthropological Theory of the Didactic, every object which has a materiality and which is perceptible, such as sound, gesture, diagram, geometrical instruments, is by definition an ostensive. These authors distinguish the instrumental valence of the ostensive - what is made possible by the ostensive - and the semiotic valence of the ostensive - what it allows to be evoked (Wozniak 2013). Thus, 'All these repeated observations show that semiotic representations constitute an irreducible aspect of mathematical knowledge and that wanting to subordinate them to concepts leads to false issues in learning' (Duval 1999, p. 8).

In the present paper, we look at the written productions (drawings, written numbers, etc.) by very young pupils, in situations with some materials (necklaces which had to be reproduced in various situations). The object (the necklace) was therefore present and its material characteristics, essentially visual, are important (size and colour of the beads, length of the necklace, shape of the knot, etc.). Pupils of this age know the written representation of numbers (in this case, up to at least 10), yet many authors insist not only on the importance of visual representations and visualisation but also on the relationship between several representations in learning mathematics (Douady 1991; Rivera 2010).

We therefore consider that written representations (drawings, written numbers, the association of both) produced by pupils in a functional context may be analysed from two points of view. On the one hand from the point of view of their efficiency in a situation (do they allow the task to be successfully accomplished?), but also on the other hand from the point of view of what they reveal of the conceptualisation of numbers as coordinates on the number line. Involving very young pupils, we try to understand, according to our research questions, 'how signs are produced already in elementary, initial mathematical learning processes' (Steinbring 2006, p. 157).

\section{Task design}

\subsection{Presentation of the design}

The design was based on six phases which are presented briefly here:

- Phase 1: Installation of the milieu

- Phase 2: Action: replication of a model necklace

- Phase 3: Formulation with model and replication in two different places 
- Phase 4: Formulation with model and replication in two different moments

- Phase 5: Formulation with communication with others

- Evaluation.

The sequence began with the discovery of the milieu. A necklace was made by each pupil with 10 beads, including a coloured one, and a thread with a knot at one end. Afterwards the pupils had to compare all the necklaces made the same way. In this first phase, the comparison of the necklaces allowed the teachers to introduce the method of one-to-one comparison (Fig. 1): knot-knot; white bead-white bead and so on) as a means of comparing the position of the coloured bead in the two necklaces. During this phase, teachers and pupils agreed on the meaning of the words 'identical necklace', 'place', 'position', and 'location'.

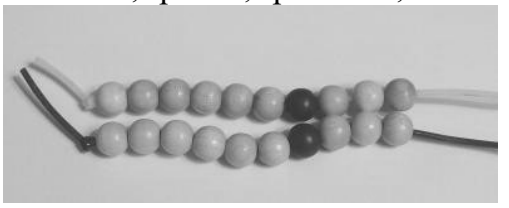

Fig. 1 Two identical necklaces

During the second phase, the teacher asked the pupils to make a necklace identical to a model. The one-to-one comparison became the validation procedure of the task. These first two phases were action situations.

They were followed by three formulation situations. In the third phase, the model was no longer visible during the reproduction. The place where the model was put and the place where the pupils had access to the beads and strings were distant. During the validation, model and reproduction were compared. The teachers only said, 'We will see if your necklace is the same as the model.' Teachers used one-to-one comparison and noted without comment the successes and failures. Teachers did not ask pupils which technique had been effective, nor did they try to identify the effective techniques themselves.

In the fourth phase, the pupils were asked to reproduce a model necklace with thread and beads given at a later time (not before the afternoon on the same day). This was the first time pupils were asked to produce a written message. The validation was carried out in the same way as before: an attitude of neutrality on the part of the teachers who noted the successes and failures using one-toone comparison.

The fifth phase was the production of a message for another pupil, enabling that pupil to make a necklace identical to the model. Each pupil was placed first in the role of transmitter then in the role of receiver of a message. During validation, the messages were analysed collectively to extract the elements of the technique allowing the task to be carried out. This was the moment when the teachers institutionalised the characteristic elements for the message to be effective. The message was expected to contain three pieces of information: the origin and the orientation of the necklace and the position of the bead compared to the origin.

During the evaluation, the pupils were invited to solve three problems: given a model, find an identical necklace in a basket of necklaces placed at a distance; devise a message (for themselves or for others) to reproduce a model necklace; and select 'the necklace with the red bead in $7^{\text {th }}$ position from the knot' from among others.

\subsection{Specific features of the 'école maternelle' in France}

Education systems which concern children younger than 6 years old vary from country to country. In France, the 'école maternelle' is a school and not a pre-school. Even though attendance is not compulsory before the age of 6 years, in practice nearly all children of 3 years of age are enrolled at school. Teachers who teach at the 'école maternelle' can also teach at elementary school. The teaching objectives are defined by a national curriculum, as for other school levels, ${ }^{2}$ and the section about mathematics is included in the 'discover the world' part. The teaching programme insists on the 'discovery of the functions of the number, especially as a representation of quantity and means of identifying positions of ordered objects in a list' and emphasises work on 'various forms of representations (drawings, diagrams)'. However, the documentation available for teachers does not focus much on ordinal numbers. Teachers use number lines (at least from 1 to 10 , and often more) or calendars (for example in Fig. 2 a part of the number line and a calendar are visible). These objects are used at least once a day when the date is written.

2 http://www.education.gouv.fr/bo/2008/hs3/programme_maternelle.htm. Accessed 10 October 2013. 


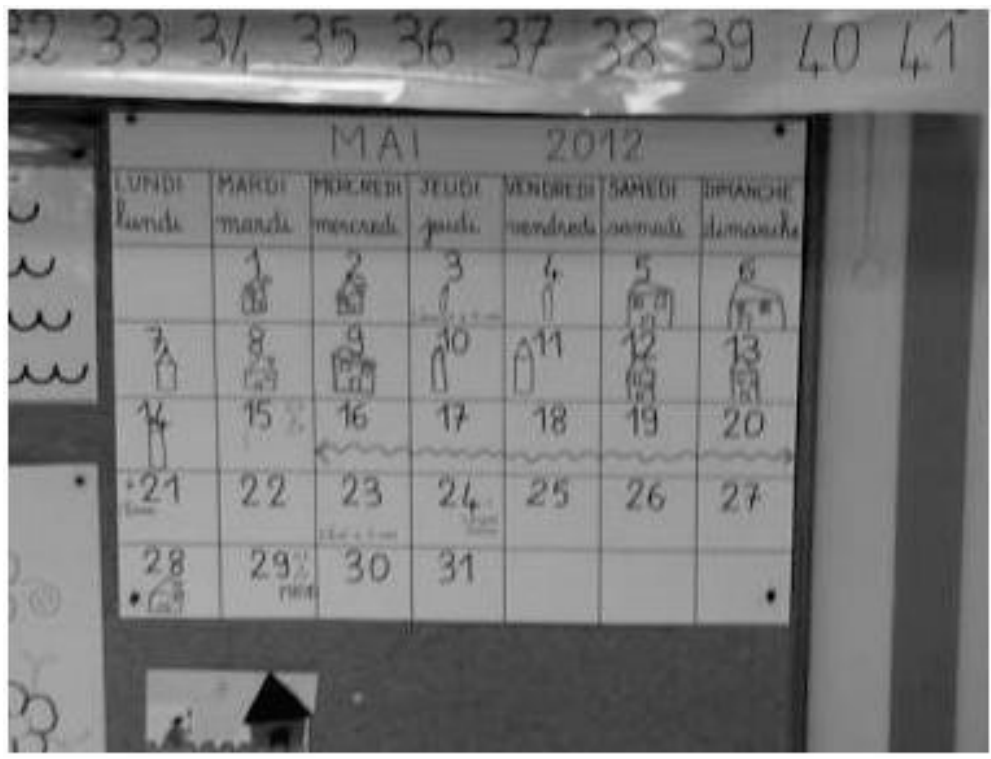

Fig. 2 A poster in one of the classrooms

For many teachers, ordinal numbers are limited to activities about the calendar. When the pupils are required to use a written number it is generally to express a cardinal, or the day's date.

\subsection{Experimental conditions and ethical considerations}

This study was carried out in two classes (5-6 years old) in May and June 2012. These teachers did not know each other and only communicated with one of us. One teacher teaches a class of 27 pupils in a socially mixed area (class A). The other teaches a class of 24 pupils in a deprived urban area (class B). The social differences of the pupils were not a concern of our research.

On the basis of the research design, the teachers were free to choose the timing of the different phases of the situations as they wanted. This flexibility allowed both teachers to specify constraints to be taken into account - the usual period of the activity, working conditions, the classroom itself, etc. From an ethical point of view, although the design had a research objective, it took place during the normal activities of the class, since it concerned knowledge present in the national curriculum. The experiment took place at the end of the school year so that it did not interfere with the teachers' programmes.

Each session was videotaped. All the pupils' written work was kept for research purposes. The anonymity of the participants was strictly respected.

\subsection{Oral and written numbers: differences between the two classes}

The pupils could speak with their classmates during phases 1 to 4 and usually they commented on what they were doing or what they were going to do. They were encouraged to do so by the teachers (who did not pass any judgment). Then, the numbers were presented orally during the two first phases in which no writing was necessary. Indeed, to succeed in the task of reproducing a model necklace, the pupils had to count the beads, and some of them counted aloud; they could also refer to the position of the coloured bead using an ordinal number (e.g. 'the coloured bead is the $\left.5^{\text {th }}\right)$. Although in our study in both classes numbers were orally present, this was not the case in the spontaneous writing.

In class B, at the beginning of phase 4, one pupil (Harut) announced that numbers were to be used. So, the pupils around him tried to use numbers. This was not surprising: the pupils were trying to understand what the teacher expected them to do. Since written numbers are generally highly valued by the teacher during non-experimental teaching, the pupils interpreted Harut's comment as a good idea. Therefore, some pupils in class B attempted to use numbers in their messages (see below for the analysis of these written productions).

In class A, no pupil wrote a number spontaneously during phases 4 and 5 . This is why in this class we added a sixth phase similar to phase 4. The pupils were asked to write a message for themselves in order to duplicate the necklace another day, writing only digits (they already knew what 'digit' meant). 


\subsection{Roles of teachers and researchers in the design}

In the clinical teaching of a substantial teaching unit 'the teacher has to follow the student's ideas in trying to solve the problem' (Wittman 1995, p. 367). The two teachers involved who agreed to take part in the experiment are very experienced (they are part-time teacher trainers), and their expertise allowed them to become involved in the experiment and understand its implications, which is essential in order to define the 'division of responsibilities' between researcher and teacher (Brousseau 2008).

We asked the teachers to stay in the background because we were interested in the observation of the pupils' procedures in precise situations. The teachers were asked to have a neutral attitude. This means that their intervention and the sharing of information about the pupils' work was intended to be limited to picking up on the expressions of the pupils and the techniques that pupils put in place themselves. That is why, during the validation, the teachers used one-to-one comparison and noted without comment successes and failures.

The neutral position of the teacher was an important methodological choice if we were to observe how the representations of the pupils evolved by themselves in the designed situations. Our objective in this experiment was not first and foremost to teach pupils what an ordinal number is, but to know the pupils' various representations better. That is why we asked the teachers not to intervene in the pupils' work but this did not prevent them from facilitating the sharing of representations.

The researcher provided the teachers with the task sequence and precise instructions. During the sequence they videotaped the interactions without intervening. They administrated the individual evaluations at the end of the sequence, asking the pupils to explain their written production when there were only numbers.

\subsection{Data analysis}

Since our paper focuses on the pupils' written production, we only mention the way this kind of data was processed. We refer to oral interactions only so that the written productions are better understood. We distinguished two main types of written productions: drawn representations and numerical representations. Then, within each of these types, we established categories and subcriteria of qualitative analysis based on the following questions: What are the different ways of representing position? What are the indications of the construction of ordinal numbers? What are the written markers of the position? We studied each piece of written material made by the pupils using these criteria. In this way, we obtained an overview of the different representations as well as a finer understanding of their progressive construction.

\subsubsection{How is it possible to communicate the position through a drawing?}

In order to explain a position, it is necessary to define the implicit coordinate system: the origin and orientation of the line. In the case of the necklaces, the threads on which the beads are strung have two ends. It is therefore possible to choose either one of the ends as the origin of the system. The choice of the origin determines the orientation which corresponds to the sense of movement from one end to the other. This is why we use the expression 'information about orientation' to refer to the elements that allow us to define a direction on the curve of the thread of the necklace. Thus, in the situation we studied, representing the knot or representing the end of the necklace was enough to communicate both the origin and the orientation. Also, when the necklaces were held vertically, the beads could fall if the knot had not been at the lower end of the thread. However, in order to recognise that the necklace was drawn vertically, information which communicated the orientation in relation to the sheet of paper, such as, for example, a letter or a number on one side of the drawing, had to be given.

Yet, representing the orientation was not sufficient to tell the position. Theoretically, a point on a curve is located thanks to its curvilinear abscissa. However, the characteristic of the material comes into play again: the coloured bead is not a point on the curve. It is a single element among 9 similar elements; it is one of the 10 on the list.

For Goody (1977), the list is the typical form of the first anthropological function of writing. It is an organised set where the origin and orientation are given. With the necklaces, none of the elements was differentiated except for the coloured bead. Therefore, a way to indicate the coloured bead and the neutral beads had to be found. The representation of the necklace was therefore a way of naming the position of the coloured bead, in the same way as writing out a whole list of names is a way of putting the position of one particular name in the list into words. We therefore classify the drawing according to three main questions: 
(1) Does the drawing give any information about orientation (e.g. a knot)?

(2) Does the drawing give any information about the actual position of the coloured bead?

(3) If the information about orientation and position are given, is the position of the coloured bead correct or not in the coordinate system?

\subsection{How is it possible to communicate the position with numbers?}

In our situations, where the number of beads remained the same (9 uncoloured, 1 coloured), only the position of the coloured bead needed to be given to be able to reproduce the necklace. An efficient way is to provide a single number to represent the position if the origin and the orientation are known. We can refer to necklace 6 to indicate that the coloured bead was in $6^{\text {th }}$ position; here 6 is an ordinal number, even when we write 6 and not $6^{\text {th }}$.

Another possibility is to name the quantity of beads that make up the necklace in the order in which they should be threaded. In this case necklace 6 could be described as 514 , which should be interpreted as 5 uncoloured beads, 1 coloured bead, then 4 uncoloured beads. It is even possible to give only the number 5 to represent the 5 uncoloured beads to be threaded at the beginning of the necklace, and leave the other data implicit. In these cases, the relevant numbers are always cardinal numbers.

It is the sense that is given to the number that determines whether an ordinal number or a cardinal number is being used. Indeed, the same necklace may be designated by the number 6 as the position of the coloured bead among the beads of the necklace (ordinal sense) or by the number 5 as a quantity of the first uncoloured beads to be placed before the coloured bead (cardinal sense). Such a sense may be implicit in the self-formulation (phases 3,4 and 6), but must be explicit for communication with others for it to be efficient (phase 5).

We therefore classify the written numbers according to two main questions:

(1) Do the numbers give some information about the quantity involved in the beadworks?

(2) Can the numbers be considered in an ordinal perspective?

\section{Results and analysis}

We examine the written material made by the pupils without distinguishing the classes or the phases when the representations were made. We consider the drawn representations followed by the numerical representations.

\subsection{Messages with drawing}

\subsubsection{How did pupils represent orientation?}

The effect of the material was noticeable on the types of representation. In class A the thread is rigid and the beads do not slide easily along it. Thus the representations of the necklaces were more like segments as in Fig. 3. By contrast, in class B, the thread was not rigid and some pupils placed the necklaces in a vertical position for comparison. Thus, there were representations which used this physical phenomenon to represent the orientation of the necklace. For instance, Melania (Fig. 4), used the verticality, thanks to writing her first name and drawing a smiley which indicated the orientation of the sheet of paper.

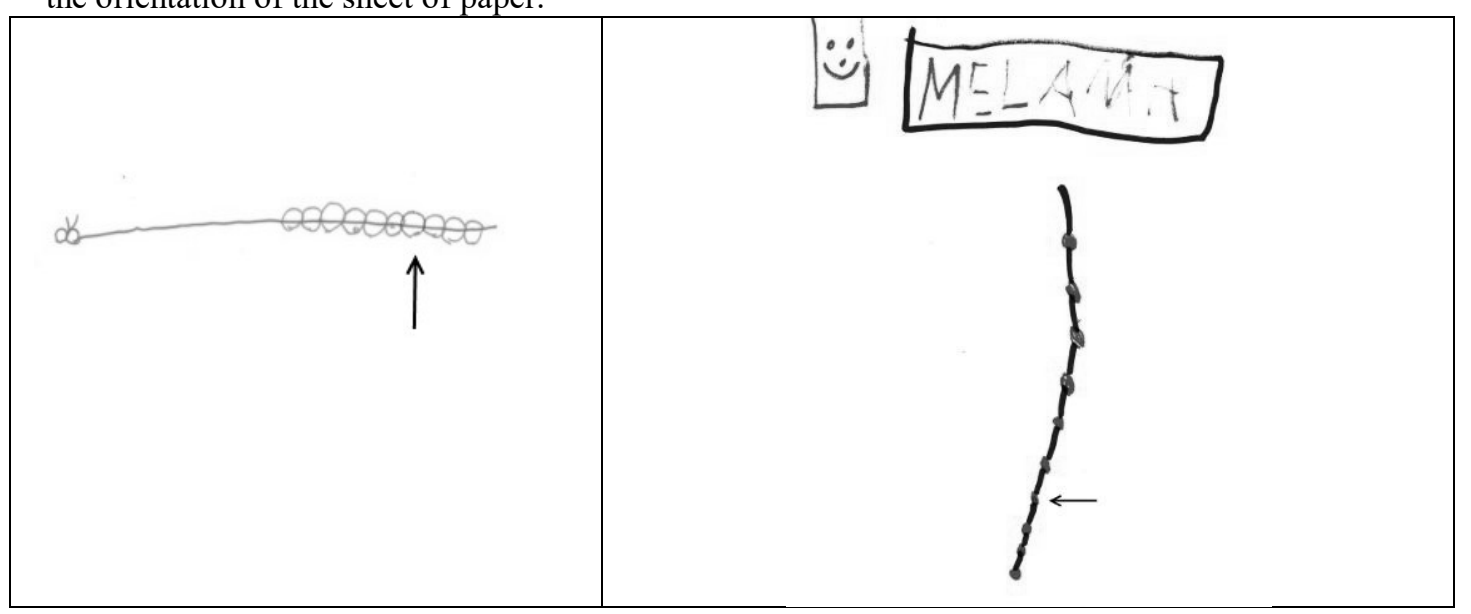


Fig. 3 A1, Eliot, phase 5, necklace $7^{3}$

Fig. 4 B1, Melania, phase 4, necklace 4

These led to a certain consistency in the representations in class A: segments with a sign to represent the knot. In class $\mathrm{B}$, however, there was great variety in the representations of the orientation: if one considers the presence (or not) of the knot, the presence (or not) of the end of the necklace and the use (or not) of the verticality, we observe that out of the eight possible cases, ${ }^{4}$ seven are represented.

Nevertheless, some drawings, very well drawn besides, showed that the pupils do not always try to represent the real object identically. This is the case for example with Kanaë (Fig. 5) whose necklace shows the orientation (the knot) and also the position of the coloured bead, but whose colours were completely different from the real ones (the model necklace had nine white beads and one blue). This is also the case of Tesnime (Fig. 6) whose drawing shows no mark of orientation but where the beads were alternately coloured (one red, one blue) although the model necklace had nine white beads and one green.

\begin{tabular}{|l|l|}
\hline Fig. 5 A2, Kanaë, phase 4, necklace 5 & $\begin{array}{l}\text { Fig. } 6 \text { B2, Tesnime, phase 4, necklace 8. The } \\
\text { beads alternate: one red, one blue, one red, one } \\
\text { blue, and so on }\end{array}$ \\
\hline
\end{tabular}

Some drawings show the difficulty of the pupils in producing a representation of the orientation of the necklace, as in Fig. 7. Nevertheless, in most of the drawings without orientation, the position is respected for one of the possible orientations of the necklace, as in Fig. 8.

Fig. 7 A2, Sanaa, phase 4, necklace 8. Some
beads are pink (one big and some small ones)
and others violet
These productions (Figs. 5 to 8 ) reveal that the pupils did not simply draw whecklace 6
tried to represent, sometimes with difficulties, what they perceived as the main characteristics of
the necklaces. By adding up all the representations drawn during the experiment, we obtained 113
drawings. Among these, 82\% include some indicators about the orientation of the drawing. It is
possible to question whether such an indication was intentional: it could be the result of an attempt
to draw the necklace identically. This orientation was given by the presence of the knot in $66 \%$ of

${ }^{3}$ For this figure, as for those that follow, we use the following key: A1 refers to class A, group 1 (customary mixed groups in each class, not corresponding to an academic level), the pupil's first name, phase number; necklace 7 means that the coloured bead which the pupil had to reproduce was in $7^{\text {th }}$ position from the knot. Since there is no colour in the printed version, the arrow means that one bead is different from the others.

${ }^{4}$ The only case which is not represented is the presence of the knot with the absence of the representation of the end of the necklace and the verticality. 
cases, the end of the necklace (31\%), and the use of vertical height (12\%) or by another process (such as the association with writing) in $8 \%$ of representations. It should be noted that many pupils combined several methods to indicate orientation. Thus, the majority of the drawings show a representation of the knot. The thread that was given to all the pupils already had a tied knot and this probably led them to favour this method to indicate orientation.

\subsubsection{How did pupils represent position?}

We have already seen some drawings where it is impossible to determine the position of the coloured bead, for example Sanaa's (Fig. 7) or Tesnime's (Fig. 6). Tesnime's drawing shows that it is not necessarily a question of graphic impossibility but a lack of conceptualisation of the pertinent elements. Nevertheless, of the 113 drawings, $83 \%$ contained indications of the position (one distinct bead in a set of ten beads). The position of the coloured bead is well understood by the pupils as an important element in passing on information to enable the reproduction of the necklace. Many pupils did not hesitate to use colours other than those of the model necklaces (or beads for the reproduction). This shows that they were quite capable of abstracting information about the position of other material characteristics, such as colour.

To locate the position of the bead, one has to create an orientation on a line and coordinate this orientation with the information of the position of the coloured bead. While $82 \%$ of the representations gave pertinent information about orientation, $73 \%$ gave pertinent information about position and only $59 \%$ succeeded in combining these two aspects to produce complete information that we will call 'complete messages' from now on.

The mistakes, for pupils who succeeded in drawing orientation and position, were about the use of the coordinate system. The pupils did not take into account the coordinate system implied by the elements of the drawing (knot, end, verticality), for example Melvin (Fig. 9).

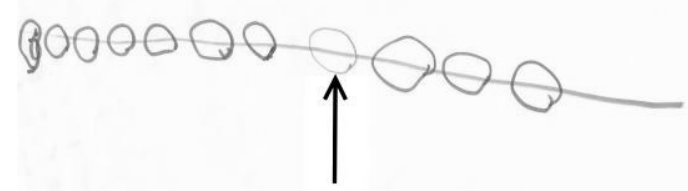

Fig. 9 B4, Melvin, phase 5, necklace 4

\subsubsection{Were the messages efficient?}

The messages produced by the pupils were not intended to represent the necklace but to retain relevant information in order to reproduce a necklace identical to the model. Therefore, we crosschecked this analysis with the necklaces produced.

\section{Incomplete messages are rarely efficient}

Forty-three drawings were produced in phase 4 of self-formulation. Among these, $38 \%$ were complete messages and $95 \%$ of them (19 drawings out of 20 complete messages) led to correct reproduction of the model necklace. The exception was Kanaë's message (Fig. 5). Among the 62\% of the drawings which were incomplete, $50 \%$ led nonetheless to success. The pupils had probably memorised the model necklace or else they remembered how to interpret elements that were not visible for us. It is not surprising that a pupil decodes the implicit in his own representation. On the other hand, in phase 5 of communication with others, there was only 1 incomplete message out of 17 which led to success $(11 \%)$. That was Melis's message, in which there are both drawing and written numbers (Fig. 10). We assume that the numbers contribute to this success, which is explored below. 


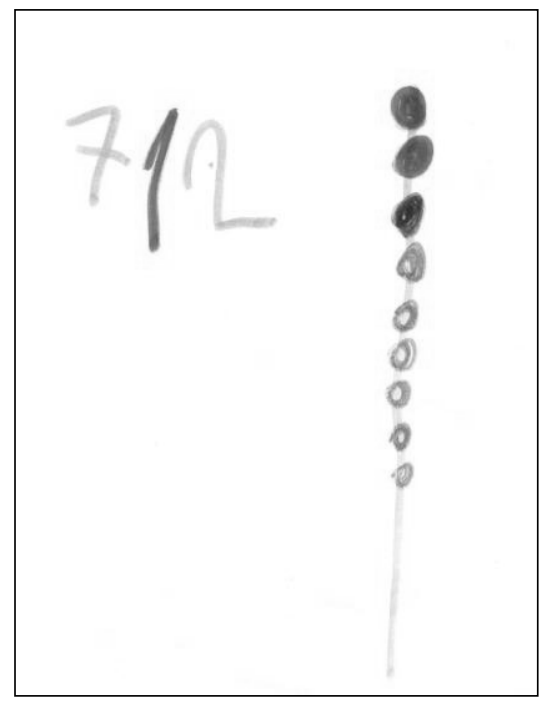

Fig. 10 B2, Melis, phase 5, necklace 8. The seven beads at the bottom are pink, then one bead is violet, the last two are green

\section{Complete messages are generally understood}

In phase 5 of communication with others, 45 drawings were produced and $62 \%$ of them were complete messages. However, of the 28 complete messages, only 23 led to the correct reproduction, that is, $82 \%$ efficiency. Thus only five pupils who received a complete message did not manage to interpret the complete representation.

The messages of Lucas, Raphaël and Zoubir were not sufficiently well-drawn: there were some ambiguous-coloured beads, crossed-out beads, or an ambiguous knot. Eliot's message was read by Noah, who had not yet produced any message including an orientation or a position. Noah read the position, since he produced a back-to-front necklace (3 instead of 7); see below for a study of Noah's case. Mahmut, who was able to produce a complete drawing from phase 4, did not understand Nawel's message (Fig. 11). However, Nawel's message included both a complete message (vertical, bead coloured green in $8^{\text {th }}$ position) and numbers. It is possible that Mahmut did not interpret the orientation with the verticality since he represented the knot and the end of the necklace in his drawings. It is also possible that he tried to interpret the mirrored written numbers unsuccessfully.

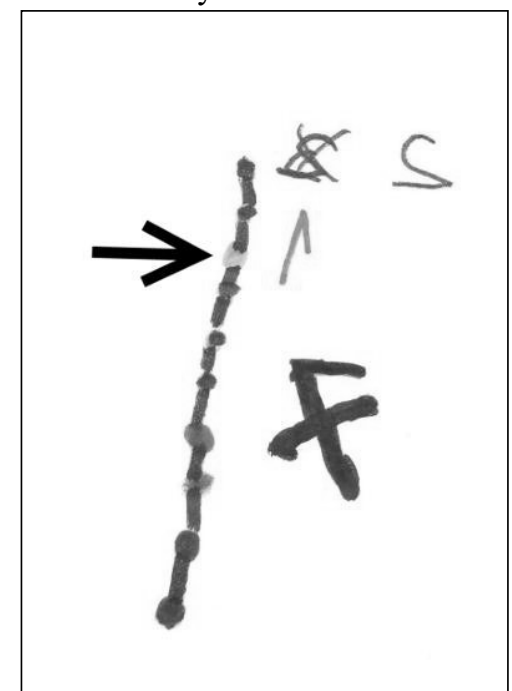

Fig. 11 B1, Nawel, phase 5, necklace 8. One bead is green; the others are brown or red

To sum up, the great majority of complete messages were well interpreted by the receivers. When this was not so, it could be due to the receiver not knowing the code used by the sender - Eliot's and Nawel's messages; or to the ambiguity of the drawing - Lucas's, Zoubir's and Raphaël's messages. 


\section{In conclusion, what do the complete messages tell us?}

In most cases, the complete representation allowed the message to be read, even when this message was far from realistic. This cross-study of the nature of the representations and the success in reading the message, especially in the case of a message to someone else, shows that it is an interpretation which requires implicit knowledge of the visual coordinate system present in the message. It seems to us, therefore, that these situations allowed the pupils to produce and use visual representations of the coordinate system.

\subsection{Messages with numbers}

\subsubsection{How did pupils use written numbers?}

By adding up all the representations with written numbers in class A (phase 6, evaluation) and in class B (phases 4 and 5, evaluation) we obtained 62 productions. In class B, 58\% of the messages with numbers were associated with drawings, while in class A there was no association of numbers with drawings. Some productions used only cardinal numbers or only ordinal numbers and others used both.

\section{Pupils' use of cardinal numbers}

Pupils used a combination of numbers, and sometimes drawings and numbers, to express the order of the quantities of uncoloured beads in respect of the necklace: $76 \%$ of the messages with written numbers used quantities. Among them, less than $14 \%$ were non-relevant representations (e.g. writing of the total number of beads, as in Fig. 6).

The relevant representation combined quantities with the order of writing. This is particularly clear in Nawel's drawing (Fig. 12): the necklace is oriented vertically according to the order in which the numbers were read (even if these numbers were mirror written, something that is frequent at this age). The numbers were written beside the quantity of corresponding beads, in the same colour and giving the same information as in the drawing.

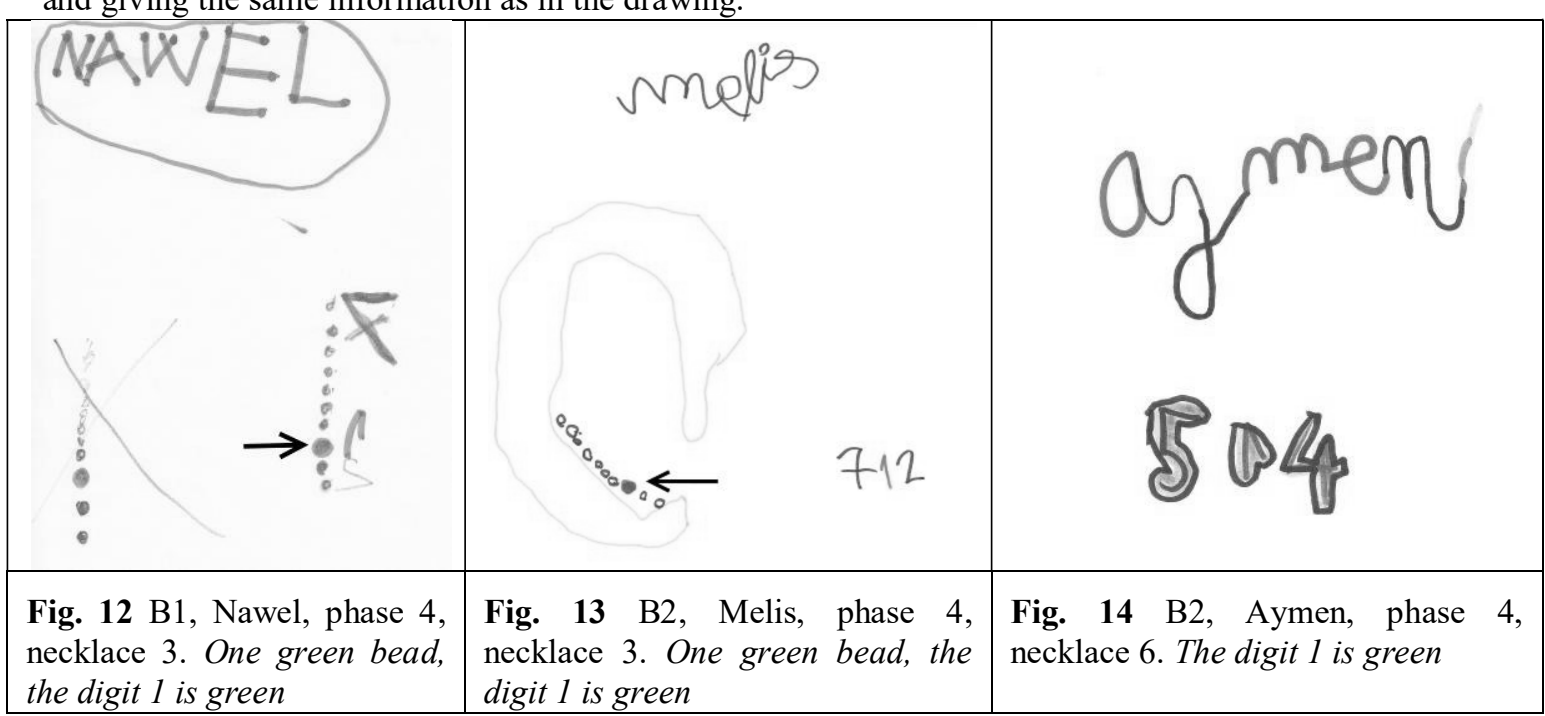

The sequences written by Melis (Fig. 13) and Aymen (Fig. 14) are a list. The numbers are to be considered in the order in which they were written. It should be noted that these pupils managed to interpret their message, when it was given to them in the afternoon, including Melis whose handwriting, if it were read from left to right, would lead to necklace 8 rather than necklace 3 .

\section{Pupils' use of ordinal numbers}

The messages using a number to express position were much rarer than the messages using quantity ( $26 \%$ of 62 productions) and, as we will see, they were rarely pertinent: $44 \%$ of the writings using some kind of ordinal number were non-functional writings.

When the teacher (class A) asked the pupils to write only numbers, with only one pencil, some of them wrote the list of numbers from 1 to 10 , for example, without any mark to show which is the coloured bead, such as Loanne (Fig. 15). 


\section{0}

Fig. 15 A2, Loanne, phase 6, necklace 7

If we consider the potentially pertinent written messages, some did not show the pupils' intention well. For instance, Yanis (Fig. 16) could not read his own message nor reproduce his model necklace. On the contrary, right from phase 4, Valmir produced writing (Fig. 17) which combined cardinal and ordinal numbers in an original way.

\begin{tabular}{|l|l|}
\hline Fig. 16 B1, Yanis, phase 4, necklace 5 & $\begin{array}{l}\text { Fig. 17 B1, Valmir, phase 4, necklace 6. The digit } \\
\text { 6is red }\end{array}$ \\
\hline
\end{tabular}

By using colour to distinguish the number of the coloured bead (6) and the other beads, Valmir made good use of the ordinal number. He associated it with two written number strings $(1,2,3,4$, 5 and $1,2,3,4)$ thereby giving the cardinal number of the uncoloured beads situated before and after the coloured bead. Despite the efficiency of this message, Valmir no longer used numbers after this.

Eva (Fig. 18) used a similar representation, in phase 6 (without colour since the teacher only gave one pencil to each pupil). Thus, in the number line, she wrote the number 6 in bold to represent the position of the coloured bead.

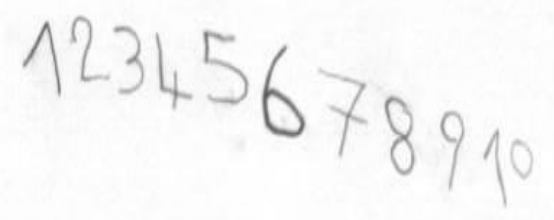

Fig. 18 A2, Eva, phase 6, necklace 6

To sum up, we have only 4 messages which truly give the position of the coloured bead using an ordinal number.

\subsubsection{Numerical representations are often correct in the coordinate system}

In our corpus, only $12 \%$ of the representations with written numbers contain an error with regard to the coordinate system of the necklace. And 6 errors out of 7 were inversions, for example 712 for necklace 3 in Melis's representation (Fig. 13).

Success was therefore higher in the marking by numerical representations $(89 \%)$ than by drawn ones $(58 \%)$. Perhaps the numerical representations led the pupils to concentrate on what is essential for the reproduction of the necklace, that is the numbers involved and the order of fabrication. The production of a drawn representation, which resembles a drawing, can focus on other criteria (aesthetics and realism with regard to the material).

\subsubsection{Numerical representations are often efficient formulations}

This analysis is based on data gathered from 43 messages using numbers excepted during evaluation.

In class B, during phase 4 (self-formulation), 5 pupils managed to reproduce the necklace out of the 10 pupils who produced messages including numbers. However, this success rate $(50 \%)$ seemed low to the pupils and led them to think that 'numbers don't work'. This may have prevented the spread of the use of the written number. Then, in phase 5 (communication with others), only 8 pupils used numbers with a success rate of $62.5 \%$. 
In class A, where numbers were imposed in phase 6 (self-formulation), all of the 14 pupils who produced a complete message managed to reproduce the model. The complete numerical message was therefore a representation of the necklace which allowed it to be replicated $(89 \%$ successfully).

\section{Discussion}

At the end of this study, we think that pupils did not simply do drawings of the necklace but sought to represent a coordinate system, using numbers in two ways: the usual (cardinal) way and an inventive (using the order of writing) way. These thoughts lead us to return to the initial question of progressive visualisation. Thus we will analyse the evolution of the representations by studying the paths taken by three pupils during the progression of the different phases.

\subsection{How does the visualisation of the coordinate system evolve during the learning unit?}

The evolution of the representations produced by some pupils shows the relation between the change of representations and the evolution of knowledge about the number line. We will follow two pupils, Walid and Noah, whose clear evolution seems to be revealing about the phases of the process.

\subsubsection{A slow positive evolution: the case of Noah and Walid}

For many pupils it is not easy to produce a representation (drawn or written) which is accurate with regard to the necklace's coordinate system. For instance, in phase 4, Walid and Noah produced very incomplete drawings (Noah rubbed out some of his).

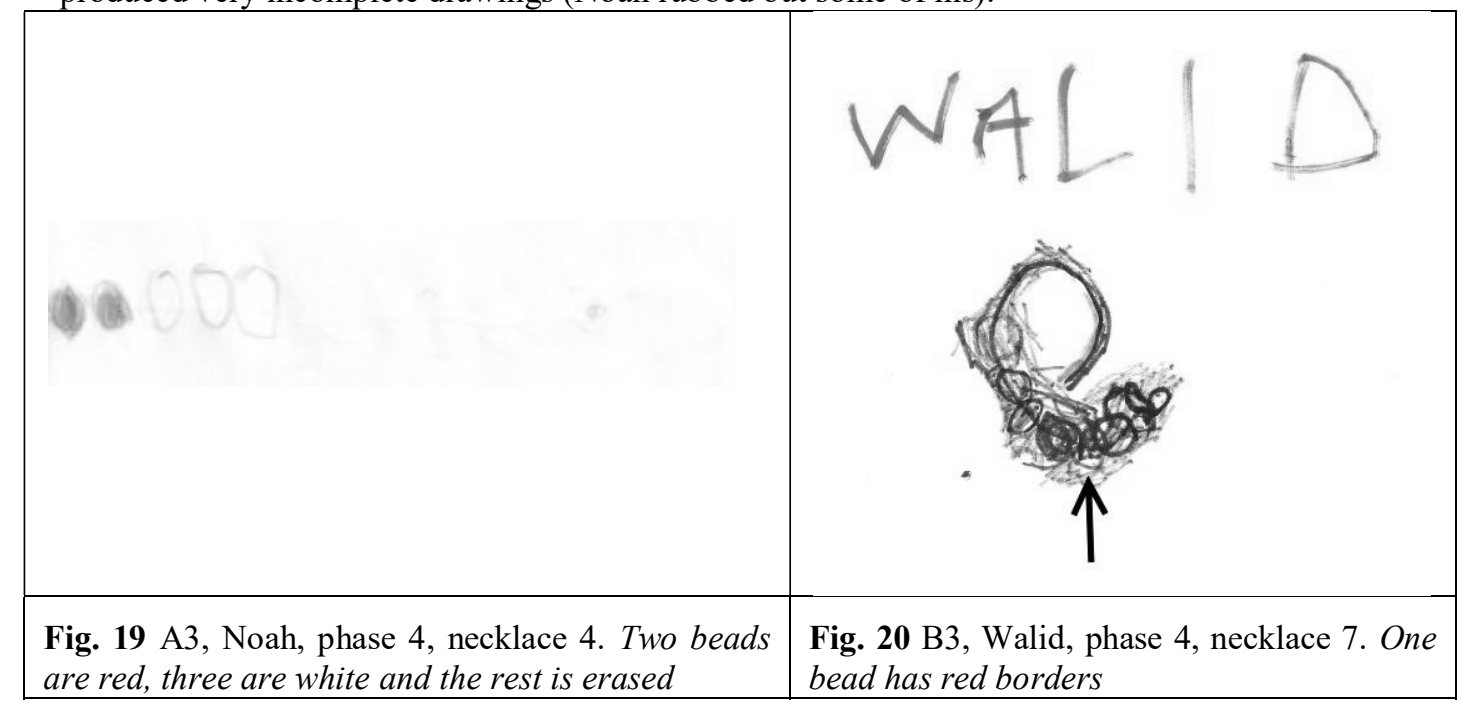

Nevertheless, in both cases, some distinctive elements were represented; Walid in particular showed the end of the necklace, a little less clearly the knot and a coloured bead. Both Noah and Walid failed to reproduce the model necklace.

When they were the transmitters of a message in phase 5, there was a greater realism in Noah's drawing (Fig. 21): ten distinguishable beads on a thread, but still no position and no orientation; whereas Walid produced a scribble in which there were no elements of position or orientation (Fig. 22). 




The receivers of these messages, whether that of Noah (Eliot) or of Walid (Betul), refuse to make a necklace: they explain that they cannot tell where to put the coloured bead. This strong feedback, not only of the material milieu (phase 4) but also from another pupil (phase 5), undoubtedly affected the evolution of the representations of Noah and Walid.

Besides this, as receivers, they both received a complete message. Noah produced a necklace 4, back-to-front compared to the model necklace: he understood the position of the coloured bead but not the orientation given by the knot. Walid was successful in producing the expected necklace, showing that he knew how to interpret the knot and thread as an orientation and the coloured bead in position 4 (Figs. 23 and 24).

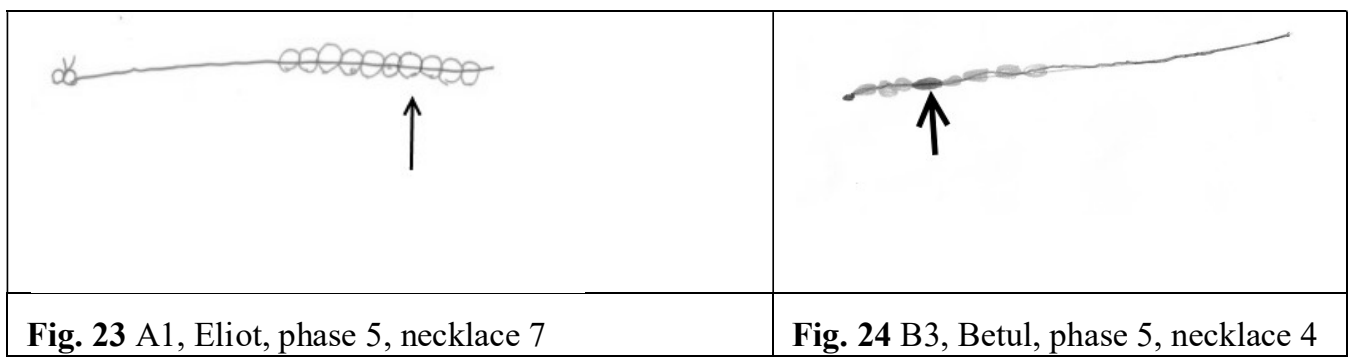

In phase 6 , Noah produced ' 4213 ' in writing for necklace 7 , which could be read successfully from left to right as 4 and 2 neutral beads at the beginning, 1 coloured bead then 3 neutral beads. Several days later, Noah was successful in reproducing the necklace. At the evaluation, Noah and Walid succeeded in making a complete representation of the necklace (Fig. 25 and Fig. 26).

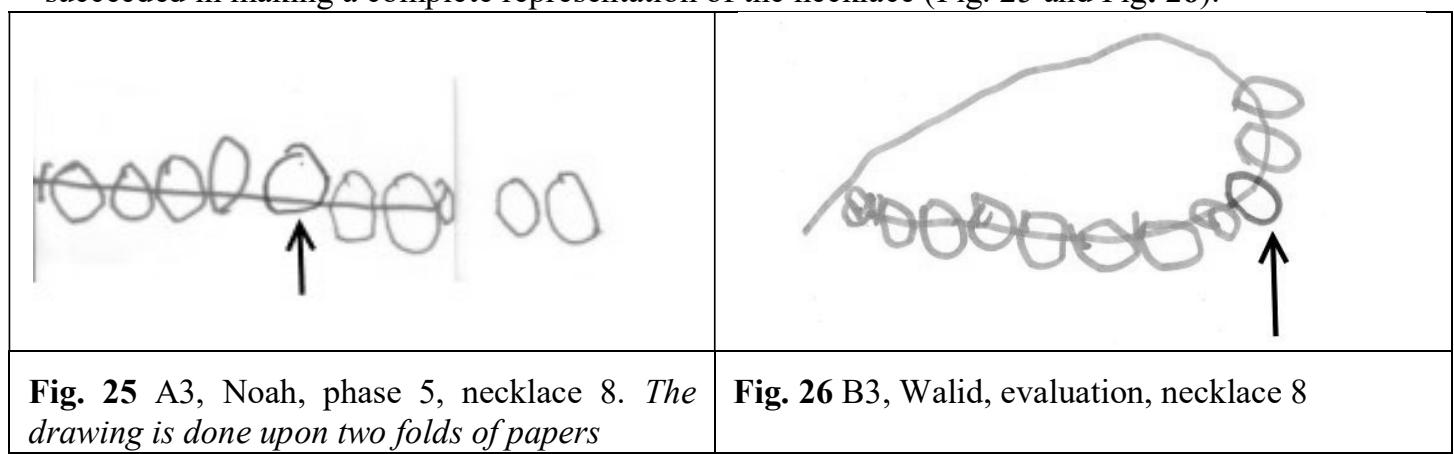

The evolution of these two pupils shows the great impact of the different phases on the evolution of the representations. The understanding of the main characteristics of the necklace arises when the pupils have to reproduce a necklace without direct access to the model. The phase 5, which contained a strong feedback for the pupils, has been a major factor leading to the evolution of the representations and to the perception of the elements useful to memorise a position.

\subsubsection{Towards the ordinal number: the case of Manon}

Only a few pupils used the ordinal number clearly to give the position of the coloured bead, in the last phases of the experiment. We give now some elements of the evolution of one of them, Manon. 


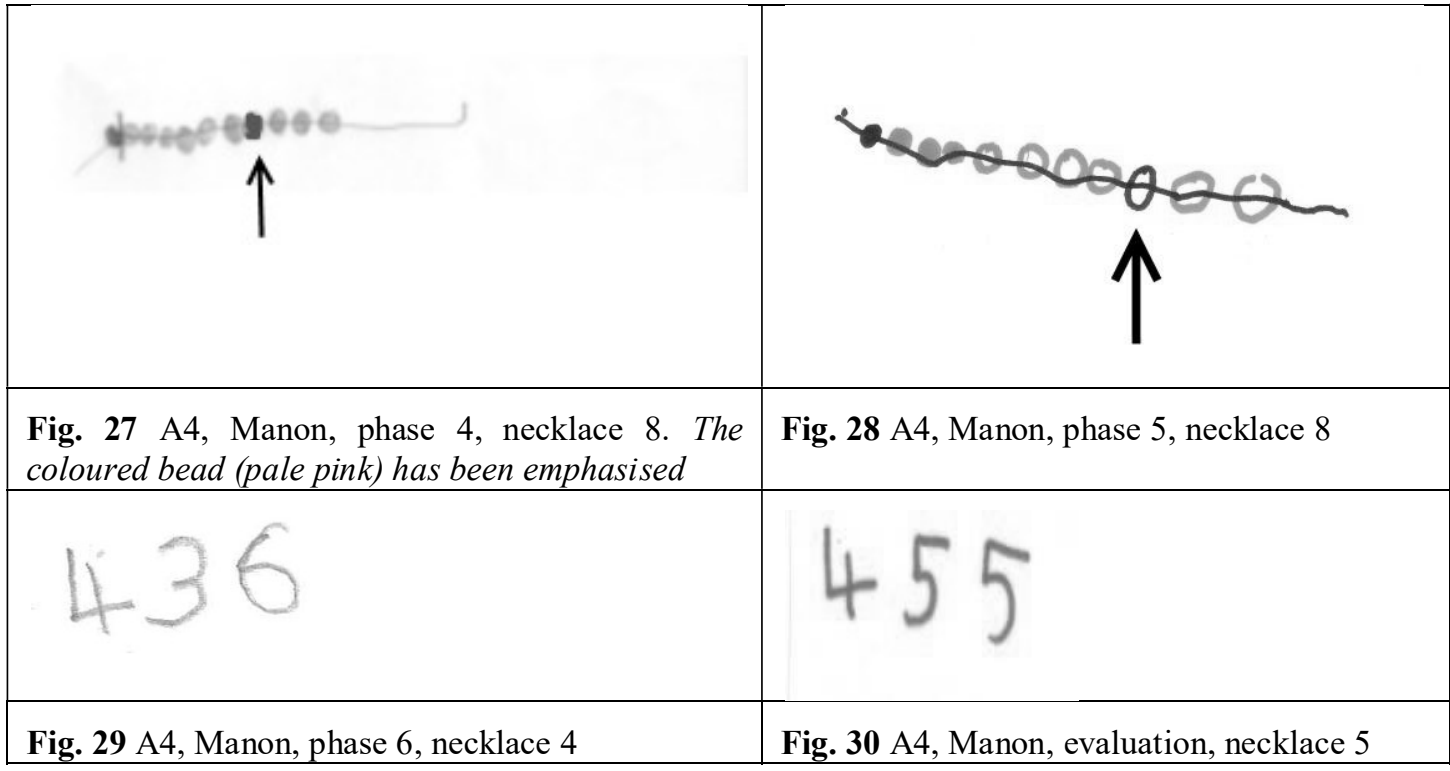

From the start, Manon understood how to use a drawn representation successfully (Fig. 27 and Fig. 28). In phase 6 (Fig. 29), she explained to the other pupils that she was using the number 4 in order to give the position of the red bead which was in the fourth place. The following numbers expressed the quantities representing the uncoloured beads on each side of the coloured bead. In the evaluation (Fig. 30) she adopted a slightly different code. Manon explained, 'First there are four white beads. It is fifth. And behind there are five white beads.' The ordinal number was thus between two cardinal numbers. Orally, she distinctly used the ordinal (fifth) for the position and the cardinal (five) for the quantity. Nevertheless, she did not go so far as to use the ordinal number alone as a message.

The evolution of the representations used by Manon seems to show that the evolution towards the ordinal number needs a good understanding of the different elements of a coordinate system. But it is not enough. The relation between cardinal number and ordinal must be clarified. The experiment did not permit her to realise that the cardinal numbers are not necessary to memorise the position and that the ordinal number alone is sufficient.

\subsection{How do pupils use numbers in order to memorise and represent a position?}

In the proposed situations, pupils had to give information allowing the point to be situated on a line in order to succeed in replicating the necklace. The pupils' initial difficulties and their evolution towards more and more efficient representations of the coordinate system confirm our hypothesis. They did not only perceive the necklace visually but they also understood that some characteristics were important where others were not: they perceived with their mind's eye (Rivera 2010). Their drawings then played the role of a sign linked at the same time to the object (the necklace) and to the concept (coordinate system), in the epistemological triangle (Steinbring 2006). We recognise here the duality between instrumental valence (the drawings are instruments to memorise information about position) and semiotic valence (they reveal the construction of the concept of a coordinate system and the role that the number can play in it). The relevant characteristics of the number line (origin, orientation and position) emerge from their interactions in the different situations.

Some pupils favour orientation first, others favour position, but the difficulty for most of them was to coordinate information concerning orientation and position. Using necklaces seemed particularly pertinent here because they provided the material characteristics of the information and therefore there was a possible milieu for validation (by one-to-one comparison). Other authors (Van den Heuvel-Panhuizen 2008; Whitney 1985) also use necklaces as a possible start to the study of the number line but their necklaces are not oriented (there is no knot), and they were designed for older pupils, to model the empty number line.

The pupils knew how to write numbers, at least up to 10 . Some of them used number writing spontaneously, associated with drawings or not, to represent a position on a line. When they were obliged to use numbers, nearly all of them understood that it was possible to use numbers to determine the position. They all showed inventiveness since they mostly produced writing that they had never seen, using three figures in the order of linguistic writing. We can connect this 
inventiveness to the work of Brizuela and Cayton (2008), who noted that pupils of the same age were capable of giving meaning to punctuation marks in numerical writing.

Outside this context, the written productions could be considered ambiguous since 316 could be read three hundred and sixteen, but in the situation these writings are perfectly readable as threeone-six. We can ask ourselves about the meaning pupils give spontaneously to numerical writing and the order of the digits in written numbers. The pupils' use of this writing echoes certain wellknown difficulties met at other levels in school, for example writing 1005 for one hundred and five. That is, using the linguistic order to write numbers, like some numbers of the Roman writing system (CV). The inventiveness the pupils show in using the linguistic order associated with numerical writing is efficient in our situations but could be an obstacle thereafter.

For almost all of the pupils, numerical writing represented quantities. The order in which these quantities should be considered to make the necklace was given by the order of the writing. The pupils had a use which conforms to the usage that they are asked to have in most situations met at school: they used the number as a reminder of the quantity. It should be noted that for those who understood the importance of coordinating orientation and position (as shown in their drawings), ordered numerical writing seemed to have the same function as the complete drawing. The pupils seemed to perceive the mathematical concept of the coordinate system in the context of the given situations. There was already a beginning of abstraction in the sense used by Steinbring (2006, p. 138): 'In processes of developing and learning mathematical knowledge, concrete objects are more and more replaced by mental objects and structures on the side of the reference object.'

The ordinal number was little present in speaking, apart from the use of the term 'first' in association with 'last' and this is consistent with the results obtained by Bruce and Threlfall (2004).

The ordinal number was also little present in written form, although it represents one of the best solutions to the problem (a single number unambiguously gives position). It is interesting to note that the few pupils who used the ordinal number associated it with other numbers: either the sequence of numbers from 1 to 10 , or the quantities of neutral beads before and after the coloured bead, the ordinal then being the number associated with the coloured bead. These pupils saw quite well that there was a dissymmetry in the role of the different beads. Thus, the coloured bead can be given by its number, but the others cannot. In writing, the absence of a mark between the number which gives quantity and that which gives position could have been a further difficulty: the use of the superscript in $4^{\text {th }}$ to mean fourth was not taught. Therefore the use of a single number did not allow the pupils to be sure of giving an unambiguous piece of information: ostensives are necessary to accomplish a mathematical task and evoke the underlying concepts.

\section{Conclusion}

Our study was motivated by the importance of the number line for the visualisation of elementary properties of operations and numbers. For the number line to be an aid for visualisation, it must be conceived as a coordinate system (origin, orientation and unit). Our study shows that pupils who are going to enter elementary school, despite knowing the number very well as something which represents quantity, fail to understand the number as something to represent position. However, they are capable, in suitable situations, of understanding the characteristic elements of the number line. We think therefore that it should be possible (as the French curriculum demands) to construct young pupils' knowledge to build the number line, through work which would bear specifically on the position-number. However, without effective teaching, it seems to us that it is not surprising that the number line is not of any help in thinking through operations, as Ernest (1985) and Van den Heuzel-Panhuizen (2008) showed. Indeed, for such a progressive visualisation of the number line to be possible, a construction of the concept of the coordinate system would have undoubtedly to take place simultaneously.

\section{References}

Ainley, J. (2008). Task design based on Purpose and Utility. ICMI 11. http://tsg.icme11.org/document/get/291. Accessed 10 October 2013.

Arcavi, A. (1999). The role of visual representations in the learning of mathematics. 23rd Conference of the International Group for the Psychology of Mathematics Education, Haifa Israel. Artigue, M. (1992). Didactique engineering. In R. Douady \& A. Mercier (Eds.), Research in didactique of mathematics (pp. 41-66). Grenoble: La Pensée Sauvage.

Artigue, M., \& Perrin-Glorian, M.-J. (1991). Didactic engineering, research and development tool: some theoretical problems linked to this duality. For the Learning of Mathematics, 11(1), 3-17. 
Bosch, M., \& Chevallard, Y. (1999). La sensibilité de l'activité mathématique aux ostensifs. Recherches en Didactique des Mathématiques, 19(1), 77-124.

Brizuela, B. M., \& Cayton, G. A. (2008). The role of punctuation marks while learning about written numbers. Educational Studies in Mathematics, 68, 209-225.

Brousseau, G. (1997). Theory of didactical situations in mathematics. Dordrecht: Kluwer.

Brousseau, G. (2008). Notes on the observation of classroom practices. ICMI 11. http://tsg.icme11.org/document/get/315. Accessed 10 October 2013.

Bruce, B., \& Threlfall, J. (2004). One, two, three and counting. Educational Studies in Mathematics, 55, 3-26.

Chevallard, Y. (2012). Teaching mathematics in tomorrow's society: a case for an oncoming counterparadigm. 12th International Congress on Mathematical Education, Seoul, Korea. http://www.icme12.org/upload/submission/1985_F.pdf. Accessed 10 October 2013.

Comiti, C. (1980). Les premières acquisitions de la notion de nombre par l'enfant. Educational Studies in Mathematics, 11, 301-318.

Csikos, C., Szitànyi, J., \& Kelemen, R. (2012). The effects of using drawings in developing young children's mathematical word problem solving: a design experiment with third-grade Hungarian students. Educational Studies in Mathematics, 81, 47-65.

Douady, R. (1991). Tool, Object, Setting, Window Elements for analysing and constructing didactical situations in mathematics In A. Bishop, S. Mellin-Olsen and J. van Dormolen (Eds.), Knowledge: Its growth through teaching. Dordrecht: Klüwer.

Duval, R. (1999). Representation, vision and visualization: cognitive functions in mathematical thinking, basic issues for learning. 23rd Conference of the International Group for the Psychology of Mathematics Education, Haifa, Israel.

Ernest, P. (1985). The number line as a teaching aid. Educational Studies in Mathematics, 16, 411-424.

Fuson, K. C. (1983). Children's counting and concepts of number. New York: Springer-Verlag.

Gelman, R., \& Gallistel, C. (1978). The child's understanding of number. Cambridge, MA: Harvard University Press.

Goody, J. (1977). The domestication of the savage mind. Cambridge: Cambridge University Press. Margolinas, C., \& Wozniak, F. (2012). Le nombre à l'école maternelle. Une approche didactique. Bruxelles: De Boeck.

Margolinas, C., Abboud-Blanchard, M., Bueno-Ravel, L., Douek, N., Fluckiger, A., Gibel, P., Vandebrouck, F., \& Wozniak, F. (Eds.) (2011). En amont et en aval des ingénieries didactiques. Grenoble: La Pensée Sauvage.

Piaget, J., \& Szeminska, A. (1941). La genèse du nombre chez l'enfant. Neuchâtel Delachaux \& Niestlé.

Rivera, F. (2010). Toward a visually-oriented school mathematics curriculum: Research, theory, practice, and issues. Dordrecht: Springer.

Sierpinska, A. (2003). Research in mathematics education: through a keyhole. In E. Simmt \& B. Davis (Eds.), Proceedings of the Annual Meeting of Canadian Mathematics Education Study Group. Wolfville, Nova Scotia: Acadia University.

Steinbring, H. (2006). What makes a sign a Mathematical Sign? - An epistemological perspective on mathematical interaction. Educational Studies in Mathematics, 61, 133-162.

Tsamir, P., Tirosh, D., Tabach, M., \& Levenson, E. (2010). Multiple solution methods and multiple outcomes - is it a task for kindergarten children? Educational Studies in Mathematics, 73, 217-231.

Urbanska, A. (1993). On the numerical competence of six-years-old children. Educational Studies in Mathematics, 24, 265-275.

Van den Heuvel-Panhuizen, M. (2008). Learning from 'Didactikids': an impetus for revisiting the empty number line. Mathematics Education Research Journal, 20(3), 6-31.

Whitney, H. (1985). Taking responsibility in school mathematics education. The Journal of Mathematical Behavior, 4(3), 219-235.

Wittman, E. (1995). Mathematics education as a 'design science'. Educational Studies in Mathematics, 29(4), 355-374.

Wozniak, F. (2013). Instrumental value and semiotic value of ostensives and task design. In C. Margolinas (Ed.), Task Design in Mathematics Education, Proceedings of ICME 22 (pp. 141152).http://hal.archives-ouvertes.fr/hal-00834054. ICMI_Study_22_proceedings_2013-10.pdf.

Accessed 10 October 2013.

Wright, R. J. (1994). A study of the numerical development of 5-year-olds and 6-year-olds. Educational Studies in Mathematics, 26, 25-44. 
Click here to download Author's Response - Commentary on the reviews: Thank your for the very accurate edition of our text.docx

Thank your for the very accurate edition of our text 